
\title{
(a)
}

\section{Structures and Optical Properties of Anodic Aluminum Oxide Thin Films}

\author{
Nitu Mandal, Mukul Dubey, Rakesh Kumar Gupta, Baibhav Ghimire, David Galipeau and \\ Qi Hua Fan
}

Department of Electrical Engineering and Computer Science, South Dakota State University, Brookings, South Dakota 57007, USA

\begin{abstract}
Low refractive index materials $(n<1.3)$ are not common in nature. However, they are essential for antireflection coatings. In this study porous anodic aluminum oxide (AAO) on glass substrate was fabricated by electrochemical oxidation and subsequent etching. The pore size was modulated from less than $80 \mathrm{~nm}$ to more than $250 \mathrm{~nm}$. The pore depth was controlled by electrochemical anodization and/or chemical etching time. It is challenging to effectively quantify the pore structures and the optical properties of such porous materials. Using spectroscopic ellipsometry, the authors showed that the AAO materials had tunable refractive index from 1.25 to 1.40 , which is ideal for antireflection coating on glass $(n=1.54)$. In addition, quantitative information on the AAO film porosity, profile structure, film thickness, dielectric constants, and roughness was also derived from the ellipsometry analysis. It was shown that the as-fabricated AAO film included trace amount of residual metal aluminum with an effective thickness $\sim 0.28 \mathrm{~nm}$.
\end{abstract}

Received on 23-04-2014 Accepted on 17-05-2014 Published on 25-06-2014

Keywords: Anodic aluminum oxidation, etching, reflectance, refractive index, spectroscopic ellipsometry.

\section{INTRODUCTION}

Reflection occurs when light propagates to an interface of two media having different refractive indices. More than $4 \%$ of incident light reflects back from a single air - glass interface [1]. Many important engineering applications, such as solar panels, require minimizing reflection loss [2-4]. Antireflection coatings are designed and fabricated for this purpose. Commonly used antireflection coatings include multiple thin layers that need precise control of the film thickness and hence are expensive [5-8].

Fundamental optics indicates that a single layer of thin film with refractive index $\sim 1.25$ on glasses can significantly reduce reflection $[9,10]$. Materials with low refractive index are not common in nature or usually suffer from poor mechanical durability (e.g. $\mathrm{MgF}_{2}$ ) [11, 12]. Porous anodic aluminum oxide (AAO) has the potential to meet these requirements. AAO is mostly a mixture of air and alumina. By tuning the materials porosity, the effective refractive index of AAO film can be adjusted between that of air (1) and alumina (1.7). Hence porous AAO on glass can serve as low-cost antireflective coating.

"Department of Electrical Engineering and Computer Science, South Dakota State University, Brookings, South Dakota 57007, USA; Tel: 605-688-5910;

E-mail: qihua.fan@sdstate.edu
AAO films have been fabricated using different methods, e.g. imprint, electron beam lithography, hard anodization, two step anodization, and others [13, 14]. AAO formed by electrochemical oxidation have been studied for many years [15-19] and have been demonstrated with promising potential for nanofabrication, anti-corrosion treatment, coloring, photonic crystals, organic light emitting diodes and humidity sensors [16, 20-25]. Also AAO on glass can improve the performance of solar cells or light emitting diodes [26, 27]. Therefore, research on the optical properties of AAO films grown on glass has attracted great interest in recent years $[15,28,29]$.

Despite broad studies on $A A O$ in the past years, many fundamental properties of AAO remain unclear [30]. Different from AAO formed on bulk aluminum, very little is known about the composition of AAO thin films formed on glass. This in turn leads to the difficulty in determining the equivalent effective refractive index of the AAO films. Lacking such basic optical parameters imposes fundamental barriers to designing antireflection coatings. In this work aluminum thin films on glass were anodized and subsequently etched to modulate the structure and porosity of AAO. Spectroscopic ellipsometry was used to determine the composition, microstructure, and effective refractive index of the AAO thin films. 


\section{EXPERIMENTAL DETAILS}

The fabrication procedure of porous AAO nanostructures on glass is shown schematically in Figure 1. Aluminum thin film of thickness $500 \mathrm{~nm}$ was sputtering deposited on glass slide $(7.6 \times 2.6 \times 0.1 \mathrm{~cm})$. The Al thin film coated glass was cut into small pieces $(3.6 \times 1.3 \mathrm{~cm})$, which were ultrasonically cleaned in Ultrasonicator FS 60D (Fisher Scientific) using DI water, IPA and acetone for 10 minutes each before anodization.

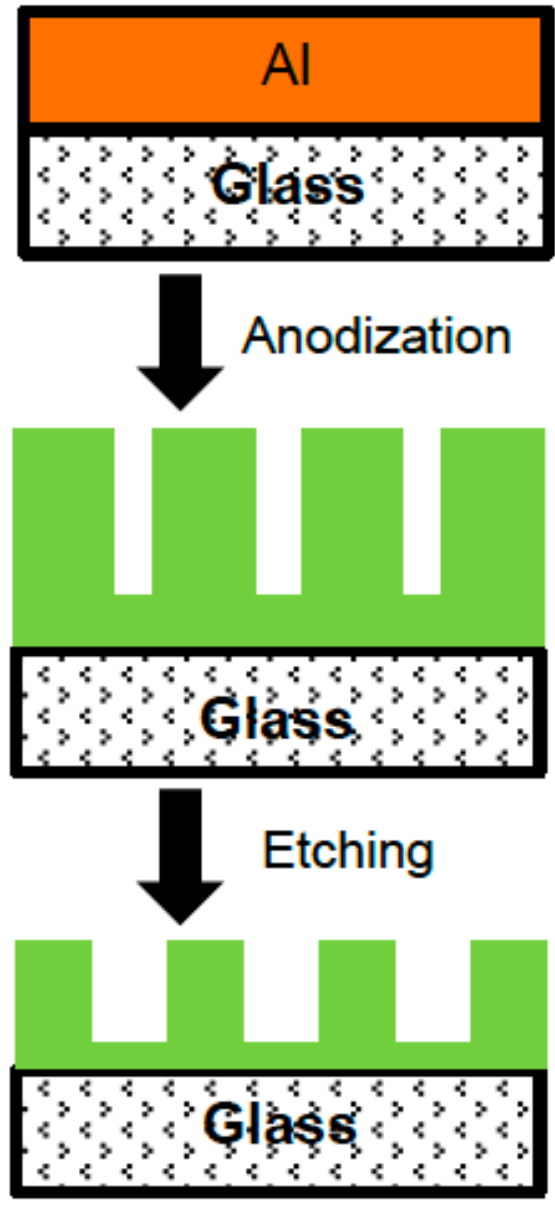

Figure 1: Schematic diagram of fabrication procedure of porous anodic aluminum oxide.

Electrochemical anodization setup is illustrated in Figure 2. The aluminum thin film coated glass was used as anode and a graphite rod of $\sim 3 \mathrm{~mm}$ diameter was used as cathode. Mixture of DI water and phosphoric acid was used as the electrolyte; the solution contained phosphoric acid of $0.05 \mathrm{v} \%$ to $0.55 \mathrm{v} \%$. Anodization was performed in potentiostatic mode with voltage ranged from $100 \mathrm{~V}$ to $160 \mathrm{~V}$. The electrolyte temperature ranged from $0^{\circ} \mathrm{C}$ to $50^{\circ} \mathrm{C}$. A beaker containing electrolyte was submerged in ice water to achieve $0^{\circ} \mathrm{C}$ and higher temperature was achieved by placing the beaker containing electrolyte on a hotplate. The DC voltage was controlled by a power supply (PAN 600-2A, Kikusui Electronics Corp.). The anodization was performed with continuous stirring. The process was completed once the current dropped to zero. After anodization, some samples were subject to etching to increase the porosity. Etching was performed using phosphoric acid at $35^{\circ} \mathrm{C}$ for 20 and 70 minutes.

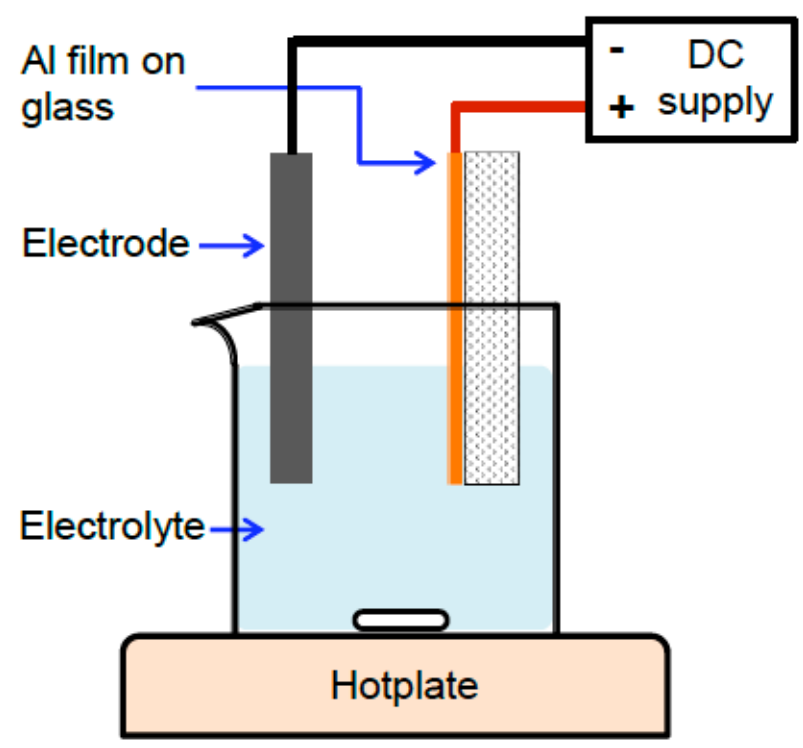

Figure 2: Electrochemical anodization setup.

Surface morphology and cross section of the anodized samples were analyzed using Hitachi S-3400 N Scanning Electron Microscope (SEM). Reflectance was measured using Filmetrics F-20 optical spectrophotometer. In order to obtain the effective refractive index of the AAO films and to understand the materials structures, spectroscopic ellipsometry measurement was performed using J. A. Woollam M2000 system and the data fitting was completed using the attached software Complete Ease.

\section{RESULTS AND DISCUSSION}

The major process parameters in AAO included anodization voltage, electrolyte concentration, process temperature, and post etching. First, the as-deposited aluminum thin film on glass was anodized at three different voltages, $100 \mathrm{~V}, 130 \mathrm{~V}$ and $160 \mathrm{~V}$. Figure 3 shows the SEM images of the resulted AAO film surfaces. It was noted that $160 \mathrm{~V}$ was close to the upper limit of a stable AAO process under current conditions; a higher voltage led to overheating of the electrolyte. Under current process conditions, the anodization voltage (electric field) had limited effect on the pore size. The average pore size was about 80 to $100 \mathrm{~nm}$.

Figure 4 shows the optical reflectance of the AAO films obtained under different anodization voltages. As expected, the AAO films became transparent and, as expected, their reflectance is significantly lower than the aluminum metal surface. The differences in the interference patterns of the reflection spectra indicate that the optical thicknesses of the AAO layers vary with the anodization voltage. Furthermore, it is noted that the average reflectance increases slightly in the long wavelength range, which implies that residual aluminum 

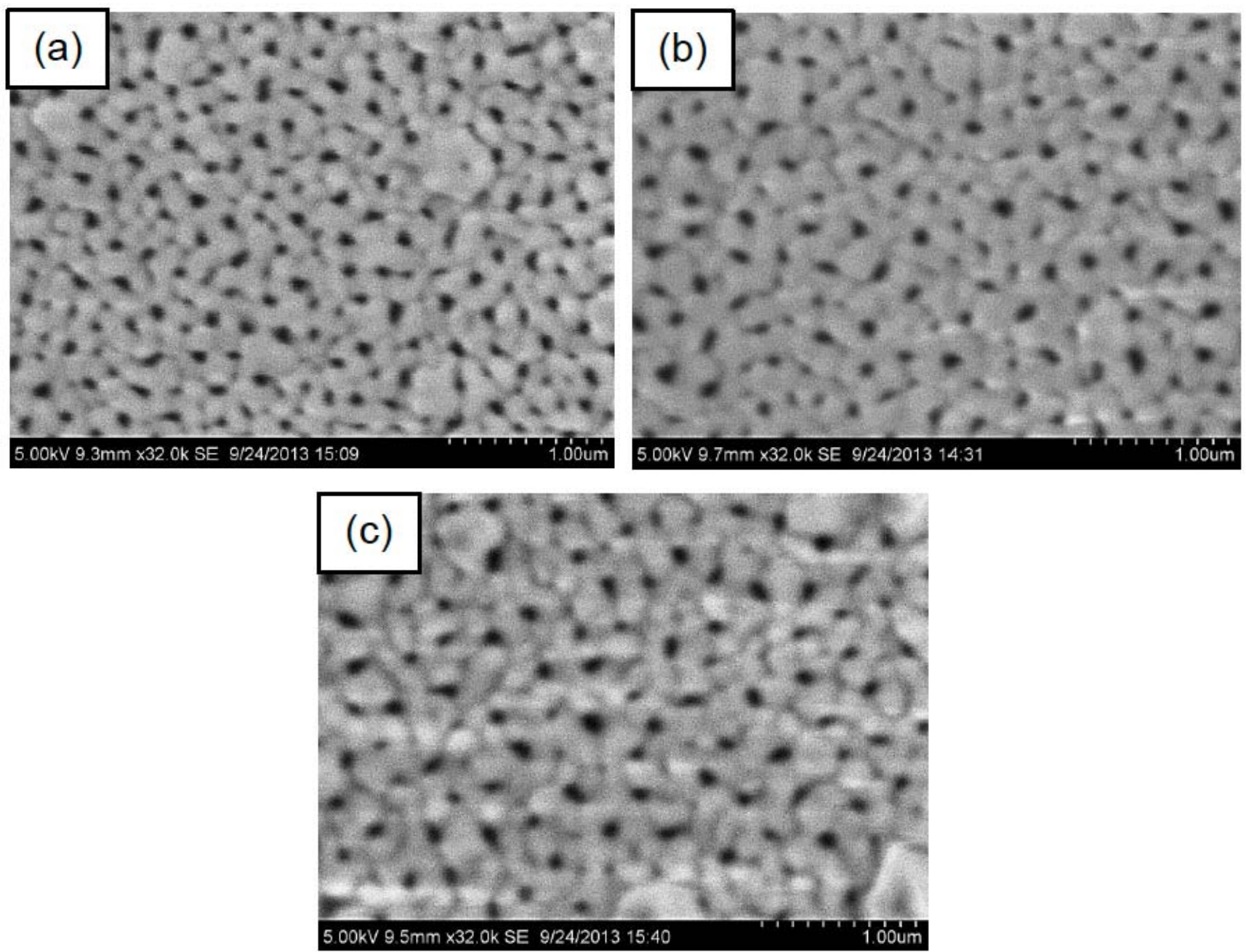

Figure 3: SEM images of AAO anodized at (a) $100 \mathrm{~V}$, (b) $130 \mathrm{~V}$ and (c) $160 \mathrm{~V}$.

might exist in the AAO, either as an ultra-thin layer or as localized dots. This will be further discussed in a later section.

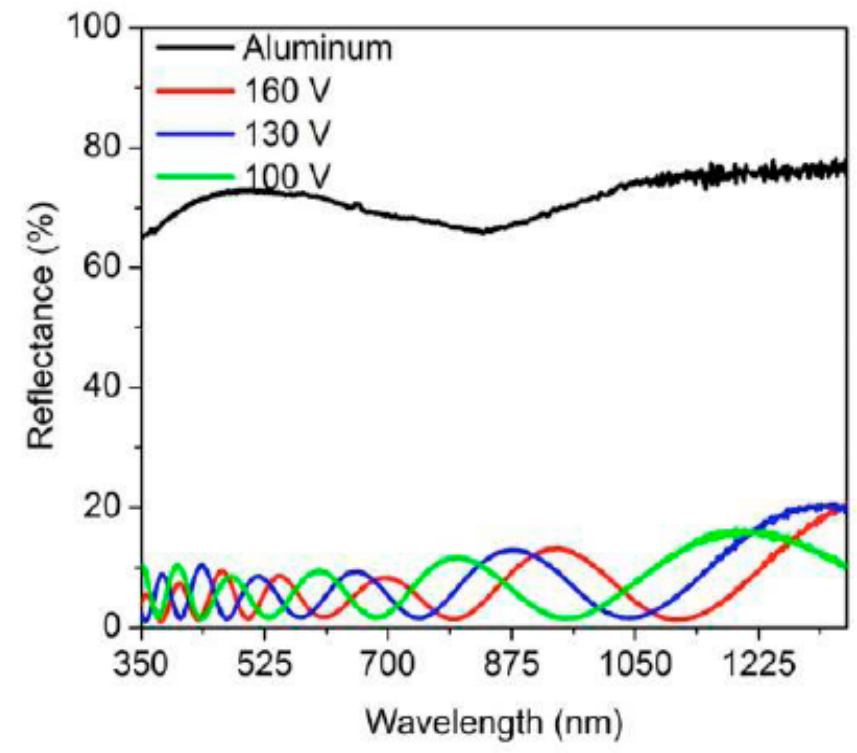

Figure 4: Reflectance of $A A O$ on glass anodized at different voltages.
The effects of the electrolyte composition on surface morphology and reflectance were also studied. Figure $\mathbf{5}$ shows the SEM images of the AAO film surfaces anodized with $0.05 \mathrm{v} \%, 0.3 \mathrm{v} \%$ and $0.55 \mathrm{v} \%$ phosphoric acid by volume in the electrolyte. Close observation indicated that slight change in the pore diameter occurred with different electrolyte concentration, but was not significant. However the anodization became faster with higher acid concentration in the electrolyte. This was due to a lower resistance of the electrolyte that led to a larger current.

Figure 6 illustrates the effect of electrolyte concentration on the reflectance of the AAO on glass. Lowest reflectance was observed for the sample anodized with $0.3 \mathrm{v} \%$ of acid. Significantly higher reflectance (particularly in the long wavelength range) is obvious for the AAO film created at higher concentration of acid (e.g. $0.55 \mathrm{v} \%$ ). The possible reason was that a high concentration of acid in the electrolyte led to faster anodization reactions, which would be nonuniform over the entire Al film, leaving behind some localized spots that might not be completely oxidized. With lower acid concentration $(0.05 \mathrm{v} \%)$, the AAO film reflectance is slightly 

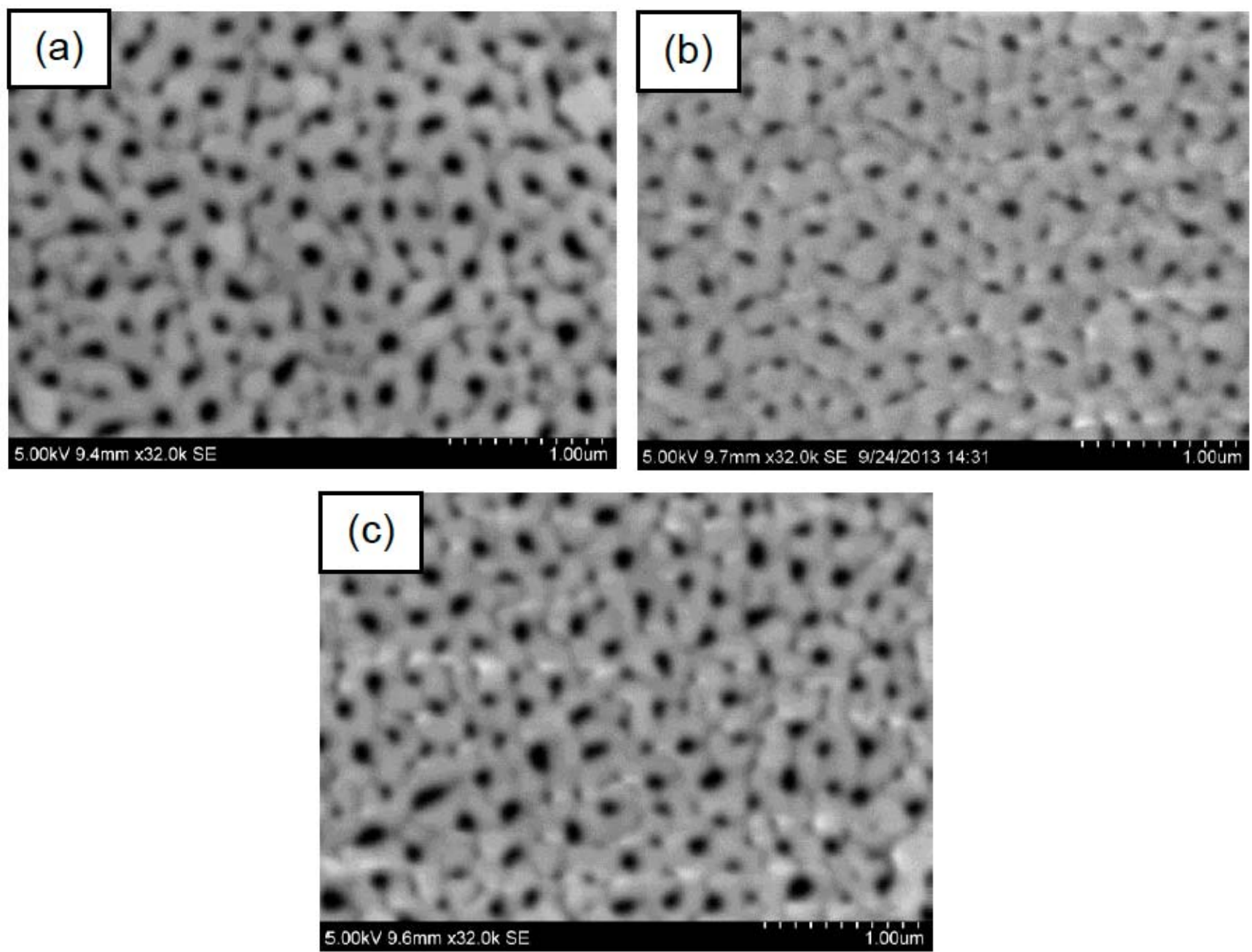

Figure 5: SEM images of AAO anodized with acid (a) $0.05 \mathrm{v} \%$, (b) $0.3 \mathrm{v} \%$ and (c) $0.55 \mathrm{v} \%$.

higher than that of $0.3 \mathrm{v} \%$ case. Hence, slow anodization did not benefit uniform oxidation.

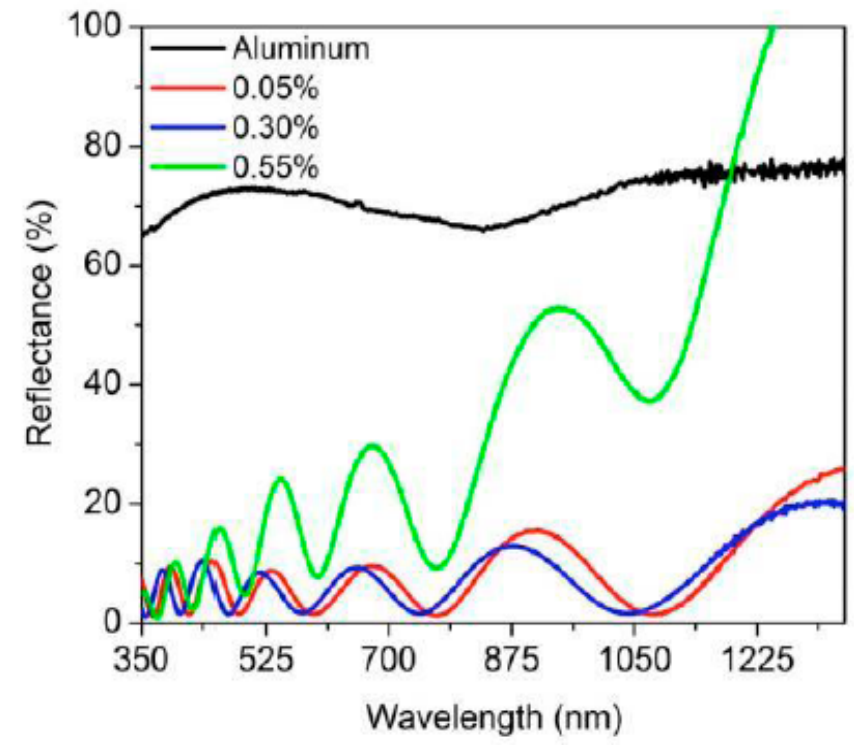

Figure 6: Reflectance of AAO on glass anodized with different electrolyte concentration.
Figure 7 show SEM images of AAO anodized at $0^{\circ} \mathrm{C}, 25^{\circ} \mathrm{C}$ and $50^{\circ} \mathrm{C}$. Observation showed that the pore size nearly did not vary with the anodization temperature. But higher temperature led to faster anodization; the anodization at $50^{\circ} \mathrm{C}$ was four times faster than that at room temperature. Figure 8 shows the optical reflection spectra of the AAO obtained at different temperatures. It can be seen that the roomtemperature fabricated AAO has the lowest reflectance, implying less residual aluminum after the anodization. It can be deduced that, at lower or higher temperatures, AAO occurs preferably or faster at defective locations (e.g. grain boundary). The AAO process would stop once the reactions reach to the point that some parts of the Al film were completely oxidized and formed a continuous matrix, while isolated islands were not fully oxidized yet. Again, further analysis will be presented in a later part regarding whether or not residual metal Al exists.

Since the anodization parameters (voltage, electrolyte concentration, and temperature) had little effect on the pore size, wet etching was conducted using a phosphoric-acidbased solution. This etching dissolution process led to increased pore size and reduced film thickness. Figure $\mathbf{9}$ 

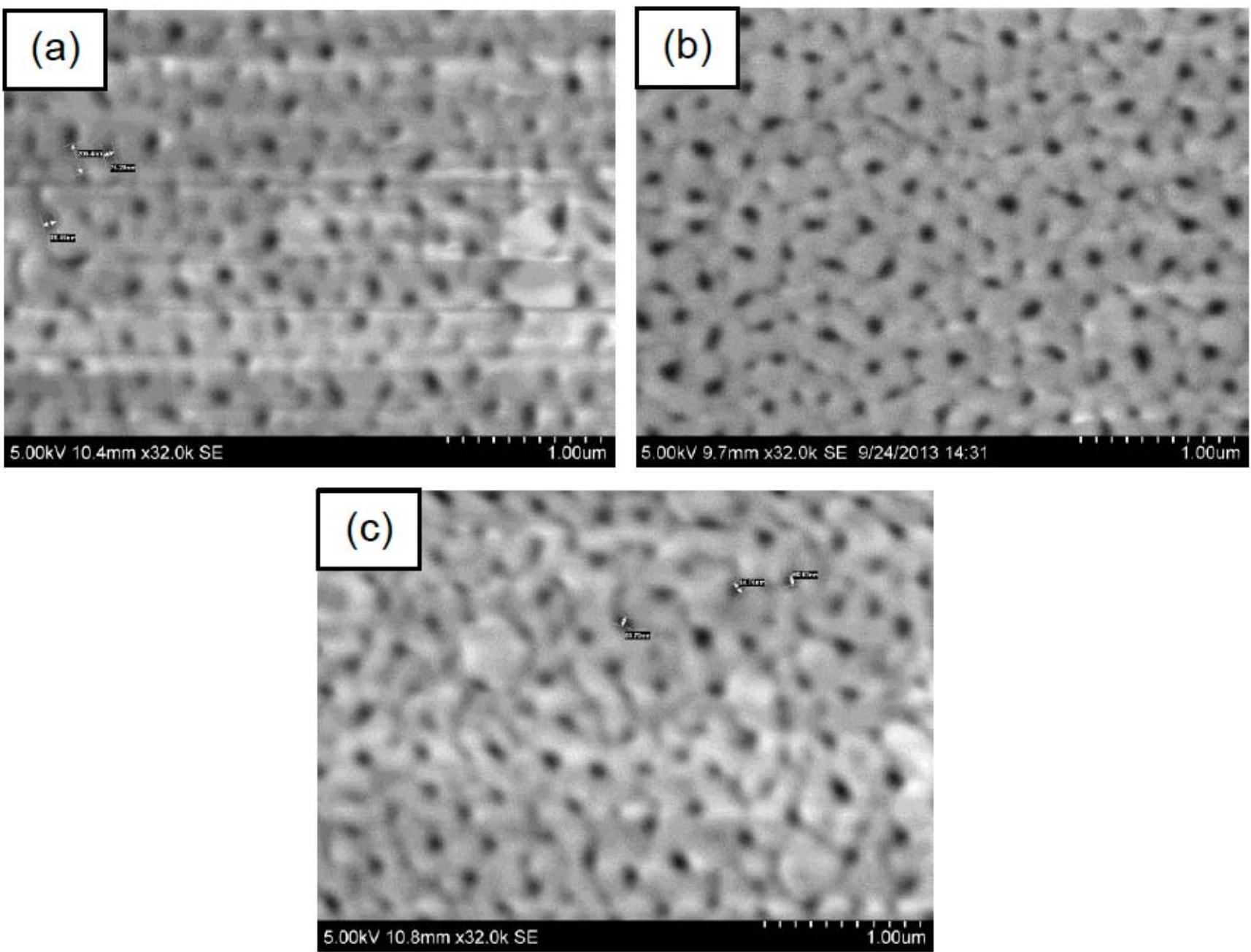

Figure 7: SEM images of $A A O$ anodized at $\left(\right.$ a) $0^{\circ} \mathrm{C}\left(\right.$ b) room temperature and $(\mathbf{c}) 50^{\circ} \mathrm{C}$.

shows SEM images of AAO surfaces before and after etching for different time. After 20 minutes etching, the average pore size increases from $90 \mathrm{~nm}$ to $150 \mathrm{~nm}$. After 70 minute etching, the pore size becomes $260 \mathrm{~nm}$. It is clear that the volume ratio of the pores in the AAO can be easily tuned using post phosphoric acid etching. This will be important to control the effective refractive index of the AAO films.

In order to use the AAO for optical coatings on glass, it is necessary to quantify the film composition, microstructure, and optical constants. Spectroscopic ellipsometry (SE) measurement and analysis were performed to obtain these characteristics. Figure $\mathbf{1 0}$ shows the SE measured psi and delta together with fitting results based on the models depicted in the figure. For the as-anodized sample (Figure 10a), the modeled film structure includes an AAO layer and an equivalent metal aluminum layer. This $A A O$ is represented by two effective medium approximation (EMA) layers; top layer approximated by Gen-oscillator and void, and next layer consisting of a dielectric material (e.g. alumina) and air void. The Gen- oscillator on top layer represents the roughness of the film. In as- anodized sample the pores are narrower at top (Figure 9), indicating the pores have inverted $V$ shape. The fitting results indicate that the top EMA layer includes 57.7\% void and has a thickness of $43.78 \mathrm{~nm}$. Next bulk EMA layer

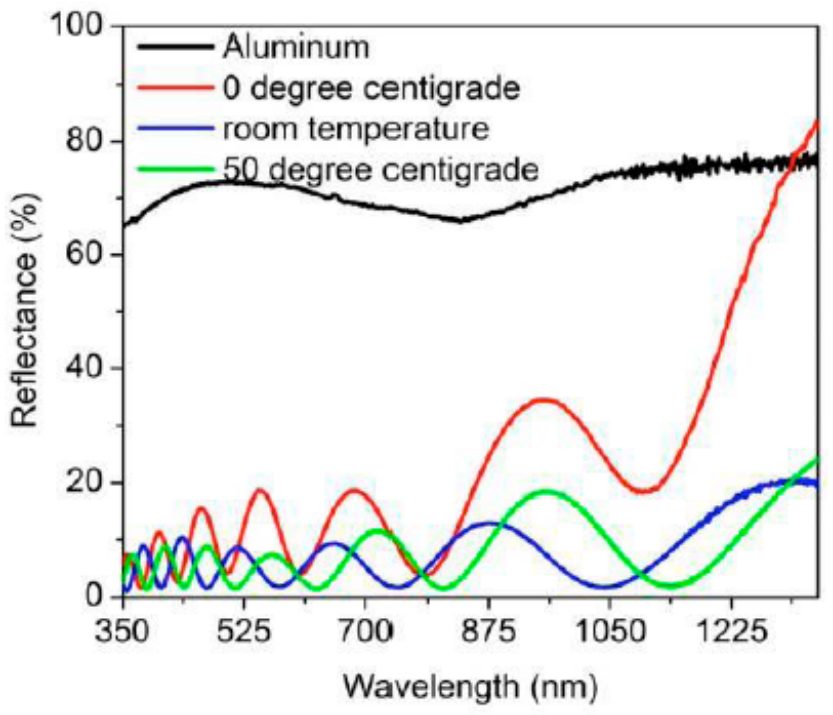

Figure 8: Reflectance of $A A O$ on glass anodized at (a) $0^{\circ} \mathrm{C}$ (b) room temperature and $(\mathbf{c}) 50^{\circ} \mathrm{C}$ 

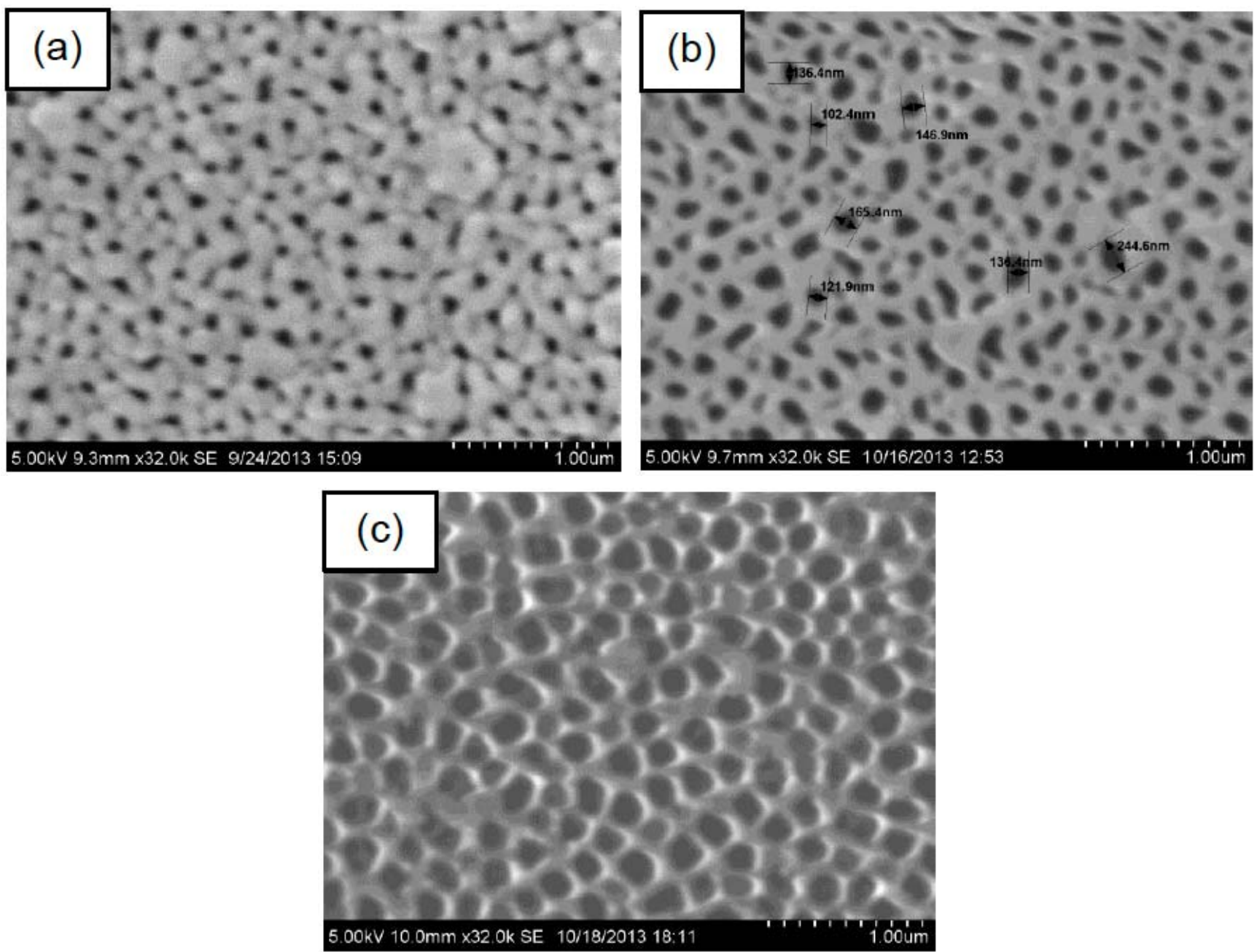

Figure 9: SEM images of AAO (a) as anodized (b) post 20 min etching (c) post 70 min etching.

contains $63.9 \%$ void and has a thickness of $1121.55 \mathrm{~nm}$. The equivalent metal aluminum layer is about $0.28 \mathrm{~nm}$. The mean square error (MSE) of the fitting is 12.008 (far below the fitting threshold value of 120), confirming good agreement between the model and the real AAO structure.

For the AAO sample after etching for 20 minutes (Figure 10b), the modeled film structure also includes an AAO layer and an equivalent metal aluminum layer. Again $A A O$ is represented by two EMA layers as before. Again the GenOscillator on the top layer signifies the roughness of the film and in this case because of etching for shorter time, pores widened up slightly compared to as-anodized case (Figure 9). The fitting results indicate that the top EMA layer has increased void, $64.8 \%$, and has a thickness of $76.14 \mathrm{~nm}$, and the second EMA layer includes $66.2 \%$ voids and has a decreased thickness of $1026.11 \mathrm{~nm}$. The equivalent metal aluminum layer remained the same thickness $0.28 \mathrm{~nm}$. The MSE of the fitting is 4.972 , indicating the model is in good agreement with the real AAO structure.

For the AAO sample after etching for 70 minutes (Figure 10c), the modeled film structure still includes an $A A O$ layer and an equivalent metal aluminum layer. Again the EMA layer for this AAO has similar composition as before but much increased air void. Here the Gen- oscillator in the top layer also represents the wider pore on top. After etching for longer time, pores widened up greatly (Figure 9), indicating now the pore shape has transformed to $V$ shape from inverted $\mathrm{V}$ shape in as anodized case. The fitting results indicate that the top EMA layer includes $87.4 \%$ voids and has a thickness of $220.29 \mathrm{~nm}$ and the second EMA layer includes $66.0 \%$ void and has a thickness of 676.00 . The equivalent metal aluminum layer is again $0.28 \mathrm{~nm}$, confirming its presence in deeper layers. This model has MSE of 4.332.

From the spectroscopic ellipsometry analysis, the refractive index of the AAO layer in the as-fabricated and etched samples was determined. Figure $\mathbf{1 1}$ shows the effective refractive indices of the AAO films of the bulk layer. It can be seen that the refractive indices of the AAO films after etching decrease obviously compared to the as-fabricated sample. Etching for 70 minutes leads to refractive index $n$ about 1.25 and less in the visible and IR range. Therefore, this AAO layer has the potential to become an ideal antireflection coating on glass. Further research on the optical performance 

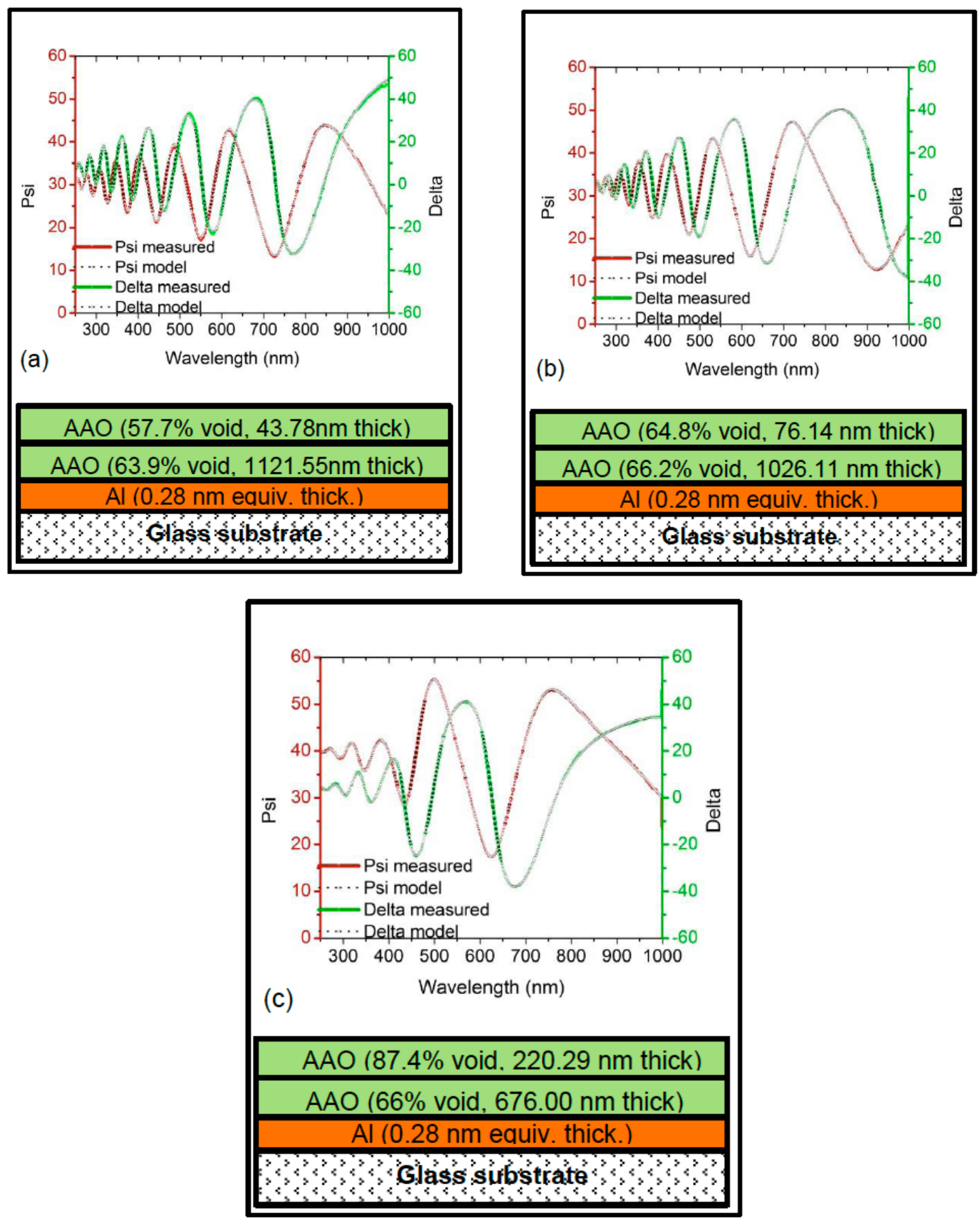

Figure 10: Spectroscopic ellipsometry measured and fitted psi and delta for (a) as-anodized AAO, (b) AAO after 20 min etching, and (c) AAO after 70 min etching.

of such AAO films is underway. Furthermore, the optical role of the residual metal aluminum needs clarification.

\section{CONCLUSIONS}

The anodization voltage, electrolyte concentration and temperature do not have significant effect on the pore structures of anodic aluminum oxide. However, higher electrolyte temperature and phosphoric concentration lead to faster anodization. The as-fabricated AAO has small pore size about 80 to $100 \mathrm{~nm}$ with pore volume about $63 \%$. In order to use the AAO for antireflection coating on glass, the pore size should be enlarged to reduce the effective refractive index. Etching in phosphoric acid can tune the pore size, leading to effective refractive index about 1.25 , suitable for antireflection coatings on glass. 


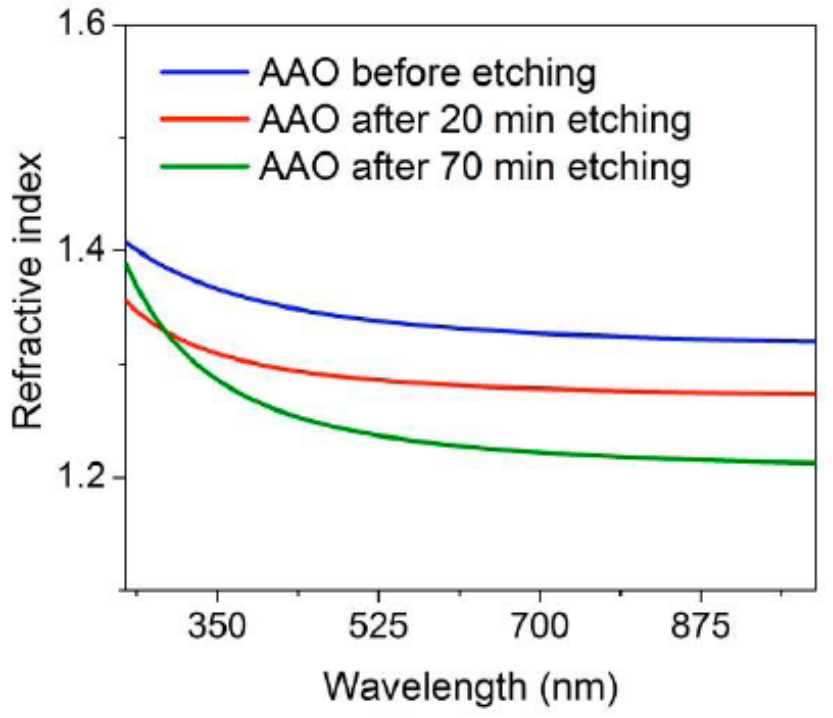

Figure 11: Effective refractive indices of AAO films on glass.

\section{ACKNOWLEDGEMENT}

The authors would like to thank National Science Foundation Grants No. IIP-1248454 and No. 1248970, South Dakota Board of Regents Performance Improvement Fund, and SDSU Research Scholarship Support Fund. This material is based upon work partly supported by the National Science Foundation/EPSCoR Grant No. 0903804 and by the State of South Dakota.

\section{REFERENCES}

[1] Pilkington. Glass Selection and Design with Pilkington OptiView ${ }^{\mathrm{TM}}$ Low Reflective Coated Glass 2014. Available: http://www.pilkington. com/resources/designpilkingtonoptiviewats184.pdf

[2] Homier R, Jaouad A, Turala A, Valdivia CE, Masson D, Wallace SG, et al. Antireflection Coating Design for Triple-Junction III-V/Ge HighEfficiency Solar Cells Using Low Absorption PECVD Silicon Nitride. Photovoltaics IEEE J 2012; 2: 393-397.

\section{http://dx.doi.org/10.1109/JPHOTOV.2012.2198793}

[3] Yang T-C, Lee B-S, Yen T-J. Minimizing reflection losses from metallic electrodes and enhancing photovoltaic performance using the Si-micrograting solar cell with vertical sidewall electrodes. Appl Phys Lett 2012; 101: 103902.

\section{http://dx.doi.org/10.1063/1.4749838}

[4] Moushumy N, Das N, Alameh K, Lee YT. Design and development of silver nanoparticles to reduce the reflection loss of solar cells. in High Capacity Optical Networks and Enabling Technologies (HONET) 2011; 2011: 38-41.

[5] Selj J, Thøgersen A, Foss S, Marstein E. Optimization of multilayer porous silicon antireflection coatings for silicon solar cells. J Appl Phys 2010; 107: 074904.

http://dx.doi.org/10.1063/1.3353843

[6] Das N, Islam S. Optimization of nano-grating structure to reduce the reflection losses in GaAs solar cells. in Universities Power Engineering Conference (AUPEC) 2012; 22nd Australasian, 2012: 15.

[7] Yeh Y, Ernest F, Stirn R. Practical antireflection coatings for metal-semiconductor solar cells. J Appl Phys 2008; 47: 4107-4112. http://dx.doi.org/10.1063/1.323270

[8] Chhajed S, Schubert MF, Kim JK, Fred Schubert E. Nanostructured multilayer graded-index antireflection coating for Si solar cells with broadband and omnidirectional characteristics. Appl Phys Lett 2008; 93: 251108-251108-3.

http://dx.doi.org/10.1063/1.3050463
[9] Kasap SO. Principles of electronic materials and devices. McGrawHill New York, NY 2006; vol. 3.

[10] Baumeister P. Applications of thin film coatings. Optical Design, MILHDBK-141,(DOD, Washington, DC, 1962) 1962.

[11] Tien C-L, Lin T-W, Tzeng H-D, Jen Y-J, Liu M-C. Temperaturedependent optical and mechanical properties of obliquely deposited MgF2 thin films. Indian J Pure Appl Phys 2014; 52: 117-123.

[12] Thielsch R, Pommies M, Heber J, Kaiser N, Ullmann J. Structural and mechanical properties of evaporated pure and mixed MgF2-BaF2 thin films. Optical Syst Design Product 1999: 539-548.

[13] Huang K, Li Y, Wu Z, Li C, Lai H, Kang J. Asymmetric light reflectance effect in AAO on glass. Optics Express 2011; 19: 13011309. http://dx.doi.org/10.1364/OE.19.001301

[14] Lee W, Ji R, Gösele U, Nielsch K. Fast fabrication of long-range ordered porous alumina membranes by hard anodization. Nat Mater 2006; 5: 741-747.

http://dx.doi.org/10.1038/nmat1717

[15] Chen J, Wang B, Yang Y, Shi Y, Xu G, Cui P. Porous anodic alumina with low refractive index for broadband graded-index antireflection coatings. Appl Optics 2012; 51: 6839-6843.

http://dx.doi.org/10.1364/AO.51.006839

[16] Lu C, Chen Z. Anodic Aluminum Oxide--Based. Encyclopedia Nanosci Nanotechnol 2011; 11: 235-259. http://www.engr.uky.edu/ zhichen/publication/AAO\%20Review\%20-Reprint.pdf

[17] Sheng X, Liu J, Coronel N, Agarwal AM, Michel J, Kimerling LC. Integration of self-assembled porous alumina and distributed bragg reflector for light trapping in $\mathrm{Si}$ photovoltaic devices. Photonics Technol Lett IEEE 2010; 22: 1394-1396. http://dx.doi.org/10.1109/LPT.2010.2060717

[18] Hoang XT, Nguyen DT, Dong BC, Nguyen HN. Fabrication of carbon nanostructures from polymeric precursor by using anodic aluminum oxide (AAO) nanotemplates. Adv Nat Sci Nanosci Nanotechnol 2013; 4: 035013. http://iopscience.iop.org/2043-6262/4/3/035013/pdf/20436262_4_3_035013.pdf

[19] Kim DS, Lee HS, Lee J, Kim S, Lee K-H, Moon W, et al. Replication of high-aspect-ratio nanopillar array for biomimetic gecko foot-hair prototype by UV nano embossing with anodic aluminum oxide mold. Microsyst Technol 2007; 13: 601-606. http://dx.doi.org/10.1007/s00542-006-0220-1

[20] Xiong G, Elam JW, Feng $\mathrm{H}$, Han $\mathrm{CY}$, Wang $\mathrm{H}-\mathrm{H}$, Iton LE, et al. Effect of atomic layer deposition coatings on the surface structure of anodic aluminum oxide membranes. J Phys Chem B 2005; 109: 1405914063.

http://dx.doi.org/10.1021/ip0503415

[21] Gâlcă AC, Kooij ES, Wormeester $\mathrm{H}$, Salm C, Leca V, Rector JH, et al. Structural and optical characterization of porous anodic aluminum oxide. J Appl Phy 2003; 94: 4296-4305. http://dx.doi.org/10.1063/1.1604951

[22] Brace AW. The Technology of Anodizing Aluminum. Modena, Italy: Interall Srl 2000.

[23] Kukhta A, Gorokh G, Kolesnik E, Mitkovets A, Taoubi M, Koshin YA, et al. Nanostructured alumina as a cathode of organic light-emitting devices. Surface Sci 2002; 507: 593-597.

http://dx.doi.org/10.1016/S0039-6028(02)01320-1

[24] Park S-J, Lee HS, Cho JH, Lee K-W. Nanoporous anodic alumina film on glass: improving transparency by an ion-drift process. Electrochem Solid-State Lett 2005; 8: D5-D7.

http://dx.doi.org/10.1149/1.1854771

[25] Masuda H, Fukuda K. Ordered metal nanohole arrays made by a twostep replication of honeycomb structures of anodic alumina. Science 1995; 268: 1466-1468. http://dx.doi.org/10.1126/science.268.5216.1466

[26] Pai Y-H, Tseng C-W, Lin G-R. Size-Dependent Surface Properties of Low-Reflectivity Nanoporous Alumina Thin-Film on Glass Substrate. J Electrochem Soc 2012; 159: E99-E102. http://dx.doi.org/10.1149/2.009205jes

[27] Zhuo H, Peng F, Lin L, Qu Y, Lai F. Optical properties of porous anodic aluminum oxide thin films on quartz substrates. Thin Solid Films 2011; 519: 2308-2312.

http://dx.doi.org/10.1016/.tsf.2010.11.024

[28] $\mathrm{He} \mathrm{Y,} \mathrm{Li} \mathrm{X,} \mathrm{Que} \mathrm{L.} \mathrm{Fabrication} \mathrm{and} \mathrm{characterization} \mathrm{of} \mathrm{lithographically}$ patterned and optically transparent anodic aluminum oxide (AAO) nanostructure thin film. J Nanosci Nanotechnol 2012; 12: 7915-7921. http://dx.doi.org/10.1166/inn.2012.6595 
[29] Liu S, Xiong Z, Zhu C, Li M, Zheng M, Shen W. Fast anodization fabrication of AAO and barrier perforation process on ITO glass. Nanoscale Res Lett 2014; 9: 159.

http://dx.doi.org/10.1186/1556-276X-9-159
[30] Jung $Y$, Byun J, Woo D, Kim Y Ellipsometric analysis of porous anodized aluminum oxide films. Thin Solid Films 2009; 517: 37263730

http://dx.doi.org/10.1016/.tsf.2008.12.051

(C) 2014 Mandal et al.; Licensee Lifescience Global.

This is an open access article licensed under the terms of the Creative Commons Attribution Non-Commercial License (http://creativecommons.org/licenses/by-nc/3.0/) which permits unrestricted, non-commercial use, distribution and reproduction in any medium, provided the work is properly cited. 